\title{
THE IMPACT OF THE COACHES' BEHAVIOR ON THE PERFECTIONISM OF ATHLETES
}

\author{
Aleksandra Aleksic Veljkovic ${ }^{1}$, Katarina Herodek ${ }^{1}$, \\ Dusanka Djurovic ${ }^{2}$, Mladen Živkovic ${ }^{1}$, Nenad Arsic ${ }^{1}$ \\ ${ }^{1}$ Faculty of Sport and Physical Education, University of Nis \\ ${ }^{2}$ Faculty of Sport and Tourism, University of Novi Sad
}

\begin{abstract}
Introduction: The coach is the person who leads, teaches and trains athletes, but most often in addition to physical and technical preparation, the coach can also perform psychological preparation of athletes in order to perform better at the upcoming performances or competitions. In the behavior of coaches, we can recognize different styles that influence each athlete and the training process and affecting their effectiveness and self-evaluation.

Aim: The main aim of the research is to determine the influence of the observed style of behavior of coaches on the perfectionism among athletes.

Methodology: The sample of respondents consisted of 99 athletes, aged 19 to 25, who are engaged in team sports (basketball, football and volleyball), with average sports experience of $8.20 \pm 3.86$ years. They completed questionnaires of Competitive Perfectionism Scale (CPS) and Leadership Scale for Sport (LSS).

Results: Mean and standard deviation scores for perfectionism were as follows, respectively: 26.07 \& 3.55 for striving for perfection; 18.11 \& 5.87 for a negative reaction to imperfection, slightly higher compared to other studies.

Conclusions: The results of this study show that there is no statistically significant connection between the perception of the coach's behavior on the perfectionism of athletes and the need for further investigation of the causes, cohesion, and consequences of behavior of sports coaches on the behavior, efficiency, and development of athletes, different sexes, ages within various sports disciplines.
\end{abstract}

Key words: coach, perfectionism, sport performance

\section{INTRODUCTION}

The relationship between a coach and an athlete is a very complex phenomenon, affected by many variables. This relationship influences the development of athletes and their sports career and is, therefore, important to examine how an athlete experiences or evaluates her/his coach and their behavior (Aleksić-Veljković, Đurović, Dimić, Mujanović, \& Živčić-Marković, 2016). Both the atmosphere and the general relationship between athletes in the team are associated with the leadership of the coaches. They depend on whether the coach is focused on improving the performance of athletes in a variety of physical training segments or is focused solely on the result, i.e. on winning the contest. If the coach is focused on performance, he or she gives positive feedback to the athletes, thereby rewarding their efforts, progress and good teamwork (Jurko, Tomljanović, \& Čular, 2013). Individual and team sports impose different expectations on coaches and athletes, their relationship included. The way athletes notice their coaches' behaviors affects all the included as well as sports achievement. It is also influenced by many psychological variables (attitudes, emotions, goals), one of the prominent ones being perfectionism.

The setting of high standards is an integral part of elite sports, often beneficial for the athlete's performance. However, those individuals who are characterized by frequent cognitions about the attainment of the ideal and by perfectionistic standards have been shown to be the likely ones to experience heightened levels of anxiety due to the discrepancies between the ideal and the current self/situation. This could, of course, be detrimental to their sports performance (Koivula, Hassme, \& Fallby, 2002). Perfectionism is a personality trait. It is desirable in sport, but in the form in which the person in pursuit of perfection feels pleasure, recognizing and accepting his own limitations. Expressed perfectionism becomes a serious problem and a disruptive factor when a person sets unrealistic expectations and is never satisfied with his/her own performance (Flett, Hewitt, \& Hill, 2016)we extend our previous analyses of the 
nature, costs, and consequences of perfectionism in athletes, dancers, and exercisers. Typically, we have emphasized the pressures inherent in having to be perfect from a perspective that considers the implications for performance as well as the toll that the need to be perfect can have on the individual athlete, dancer, and exerciser. In the current chapter, we extend our analysis by introducing the concept of 'perfectionistic reactivity.' Perfectionistic reactivity is the notion that perfectionists have a characteristic way of responding to challenges that is often not conducive to success and is potentially harmful to their well-being. In addition to describing and discussing perfectionistic reactivity and the contexts in which it is expressed, we extend our views on the nature of perfectionism and its potential costs. (PsycINFO Database Record (c. In this case, perfectionism can be viewed as a neurotic disposition that occurs with other psychopathological features such as depression and eating disorders, and may be associated with social anxiety as well as the obsessive-compulsive disorders (Bardone-Cone et al., 2007; Cassin \& Von Ranson, 2005; Hewitt, Flett, \& Ediger, 1995; Sassaroli et al., 2008). This non-adaptive perfectionism is also associated with other negative personality tendencies such as the feelings of guilt, striving for the delay, suicidal ideation, and low self-esteem (Fedewa, Burns, \& Gomez, 2005). In sports, this form of perfectionism is often found to be the cause of sports failure. Hamidi and Besharat (2010) have examined perfectionism and the onset of the competitive anxiety in athletes. The results showed that positive perfectionism was negatively related to cognitive and somatic anxiety, and positively to self-esteem. Both the appearance of a negative reaction to imperfection and negative perfectionism are accompanied by cognitive and somatic anxiety as well as low self-esteem.

There is a large number of research investigating sports perfectionism (Dunn, Dunn, \& Syrotuik, 2002; Hamidi \& Besharat, 2010; Nordin-Bates, Hill, Cumming, Aujla, \& Redding, 2014; Sagar \& Stoeber, 2009) and perceptions of the trainer behavior (Bortoli, 2015; Gesualdo, 2011; Jurko et al., 2013; Kenow \& Williams, 2016). The results of the research conducted by Djurovic, Sokic, and Aleksic-Veljkovic (2017) have shown that, during training and sports performance, the appearance of the non-adaptive protectionist tendencies, manifested in the form of the negative cognitive and emotional reactions, represent the athlete's reaction to imperfections in the performance, and can significantly affect the occurrence of the pathological behaviors (they may cause pathological eating habits).

Certainly, these are not the only possible negative reactions that can occur as a result of a highly pronounced non-adaptive perfectionism and the pursuit of success. Therefore, additional diverse research is needed in this area to obtain an answer. The aim of this research was to determine if the perceived behavior of the coach has an impact on and manifests itself in (any of the two mentioned forms) in athletes' perfectionism.

\section{METHODS}

\section{Participants}

The sample (of participants) consisted of 99 athletes, aged 19 to 25, engaged in team sports (basketball, football and volleyball), with the average sports experience of $8.20 \pm 3.86$ years. Their task was to complete the Competitive perfectionism Scale (CPS) and the Leadership Scale for Sport (LSS) questionnaires.

\section{Instruments}

The Competitive Perfectionism Scale (CPS). The CPS is a 10-item test designed and standardized by Besharat (2009) to assess the positive and the negative dimensions of competitive perfectionism. Items tap into two dimensions of perfectionism, i.e. striving for perfection and the negative reaction to imperfection, on a 5- point Likert Scale ranging from 1 (very low) to 5 (very high) (Hamidi \& Besharat, 2010).

The Leadership Scale for Sports (LSS) had five dimensions: 1) Training and Instruction (13 questions), 2) Democratic Behavior (9 questions), 3) Autocratic Behavior (5 questions), 4) Social Support (8 questions) and 5) Positive Feedback (5 questions). The LSS contained 40 items that ask athletes to indicate the frequency with which their coach engages in the specific types of coaching behavior. Item responses were based on a 5-point Likert scale, ranging from "never" to "always". The scores for each scale were calculated by summing up the item responses and dividing them by the number of items in the specific category (Chelladurai \& Saleh, 2016). 
Statistical analysis

All analyses were performed using the SPSS 20 software for Windows. For all the statistical tests, the level of significance was a priori set to $\mathrm{p}<.05$. All the data have been presented as means \pm SD.

\section{RESULTS}

The mean and the standard deviation scores for perfectionism and coaches behavior were as follows: $26.07 \& 3.55$ for striving for perfection; $18.11 \&$ 5.87 for a negative reaction to imperfection; $3.97 \&$ .66 for instructiveness; $3.29 \& .73$ for democratic behavior; $2.72 \& .73$ for autocratic behavior; 3.19 $\& .82$ for social support; $3.99 \& .71$ for positive feedback; (Table 1).

Table 1. Descriptive statistical parameters

\begin{tabular}{|c|c|c|c|c|c|}
\hline Variable & $\mathbf{N}$ & Mean & SD & Skewness & Kurtosis \\
\hline Striving for perfectionism & 99 & 26.07 & 3.55 & -.92 & -.09 \\
\hline Negative reaction to imperfection & 99 & 18.11 & 5.87 & .47 & -.89 \\
\hline Instructiveness & 99 & 3.97 & .66 & -.97 & 1.54 \\
\hline Democratic behavior & 99 & 3.29 & .73 & -.13 & .29 \\
\hline Autocratic behavior & 99 & 2.72 & .73 & .93 & 1.09 \\
\hline Social support & 99 & 3.19 & .82 & -.10 & -.29 \\
\hline Positive Feedback & 99 & 3.99 & .71 & -.76 & .91 \\
\hline
\end{tabular}

Mean - mean, SD - standard deviation, Skew. - coefficient of asymmetry, Kurt. - coefficient of curvature

Tables 2 and 3 show the impact of the variables of of perfectionism (Table 2) and the athletes' negative perception of the coaches' behavior on the pursuit response to imperfection (Table 3).

Table 2. Regression analysis parameters

\begin{tabular}{|c|c|c|c|c|c|c|}
\hline Model & $\mathbf{R}$ & R Square & $\begin{array}{c}\text { Adjusted R } \\
\text { Square }\end{array}$ & $\begin{array}{c}\text { Std. Error of the } \\
\text { Estimate }\end{array}$ & F & Sig. \\
\hline 1 & $.145^{\mathrm{a}}$ & .021 & -.032 & 3.60 & .401 & $.847^{\mathrm{a}}$ \\
\hline
\end{tabular}

$R$-multiple correlation coefficient, $R 2$ - multiple correlation determination coefficient, Adjusted $R$ Square correction coefficient of multiple correlation, Std. Error of the Estimate.-standard prediction error, F-value of $F$ test to test the significance of a predictor set on a criterion variable, p- significance level of the multiple correlation coefficient

As the result was $\mathrm{p}>.01$, it could be concluded on democracy. Providing a positive feedback, that there was no statistically significant impact together with the emphasized instructiveness, has of the mentioned variables on perfectionism in contributed to the result. athletes, or on the behavior of a coach who insists

Table 3. Regression analysis parameters

\begin{tabular}{|c|c|c|c|c|c|c|}
\hline Model & $\mathbf{R}$ & $\begin{array}{c}\mathbf{R} \\
\text { Square }\end{array}$ & $\begin{array}{c}\text { Adjusted R } \\
\text { Square }\end{array}$ & $\begin{array}{c}\text { Std. Error of the } \\
\text { Estimate }\end{array}$ & F & Sig. \\
\hline & & & & & & \\
\hline 1 & $.147^{\mathrm{a}}$ & .022 & -.031 & 5.96 & .411 & $.840^{\mathrm{a}}$ \\
\hline
\end{tabular}

$R$-multiple correlation coefficient, R2 - multiple correlation determination coefficient, Adjusted R Square correction coefficient of multiple correlation, Std. Error of the Estimate.-standard prediction error, F-value of $F$ test to test the significance of a predictor set on a criterion variable, p- significance level of the multiple correlation coefficient 


\section{DISSCUSION}

The results of the research indicate that positive perfectionism has prevailed in the sample in comparison with the negative reaction to imperfection. According to the description of the athlete, the coaches show a desire for success and insist on the performance (high instructiveness) as well as show a tendency to give positive feedback and forge the democratic behavior, thereby motivating the athletes. These are the positive and the desirable coach behaviors that contribute to the development of positive athletes, and therefore we have a small negative perfectionism and better adaptive perfectionism. There is a need to further investigate the causes, connections and consequences of the sports coaches' behavior on the perfectionism of athletes of different sex, age and sports disciplines. The mindset and the value of continuous personal development, and the progress of the coaches as well as of the athletes, are precisely that which is judged to be an important factor in long-term success. A trainer is a person who, beyond formal tasks (determining the content of training, assigning duties, setting rules, monitoring tasks, providing feedback to an athlete), influences athletic development.

The findings of the previous studies show that non-adaptive perfectionism, while continuously giving negative feedback during training sessions, significantly contributes to the pathological eating habits of the athletes in aesthetic sports (Djurovic, Sokic, Aleksic-Veljkovic, 2017). The results also show that, unlike adaptive, the non-adaptive perfectionist tendencies - the negative cognitive and emotional responses to imperfection, significantly predict pathological eating habits, explaining the $9 \%$ of variance in the criterion validity. As expected, non-adoptive perfectionism remained a significant predictor, even after the introduction of the three predictors concerning the specific trainer behaviors: negative feedback; insensitivity to the well-being of the athlete and the result-orientation. However, one of the specific behaviors of the coaches - the negative feedback, makes a significant predictive contribution, explaining an additional $10 \%$ of the variance in the pathological eating habits, in addition to the non-adoptive perfectionist demands of the athlete.

On the other hand authors Sari, Bayazlt, Soyer, Sar1, \& Talaghir (2017) have concluded that the perceived training and instruction behavior of the coaches may be beneficial for self-efficacy, general self-efficacy, intrinsic motivation and a motivation of the athletes. They have stated that the perceived autocratic behavior may be detrimental for the general self-efficacy of the athletes. As for the social support behavior, it is suggested that it is negatively related to self-efficacy, general self-efficacy and intrinsic motivation. Lastly, a positive relationship has been observed between the perceived social support behavior and the motivation in wrestlers. The results reveal the specific characteristics of the wrestlers and suggest some implications for the wrestling coaches. The findings also support that, in team sports, coaching behaviors are congruent with the athletes' individual needs and, adapted to the situational demands, may promote prosocial behavior (Lameiras, Martins, Lopes-De-Almeida, \& García-Mas, 2017).

\section{CONCLUSION}

The results of this study show that there is no statistically significant connection and the effect of perception of the coach's behavior on the perfectionism of athletes. This raises the question of the need for a further investigation of the causes, cohesion and consequences of the behavior of sports coaches on the behavior, efficiency and the development of athletes.

\section{REFERENCE}

Aleksić-Veljković, A., Đurović, D., Dimić, I., Mujanović, R., \& Živčić-Marković, K. (2016). College Athletes' Perceptions of Coaching Behaviours: Differences Between Individual and Team Sports. Baltic Journal of Sport and Health, 101(2), 61-71. Retrieved from http://www.lsu. lt/sites/default/files/dokuumentai/baltic_journal_of_ sport_2101_2016_06_29.pdf

Bardone-Cone, A. M., Wonderlich, S. A., Frost, R. O., Bulik, C. M., Mitchell, J. E., Uppala, S., \& Simonich, H. (2007). Perfectionism and eating disorders: Current status and future directions. Clinical Psychology Review. https://doi.org/10.1016/j.cpr.2006.12.005

Bortoli, L. (2015). Young Athletes' Perception of Coaches' behavior, (May), 1217-1219. https://doi.org/10.2466/ pms.1995.81.3f.1217

Cassin, S. E., \& Von Ranson, K. M. (2005). Personality and eating disorders: A decade in review. Clinical Psychology Review. https://doi.org/10.1016/j.cpr.2005.04.012

Chelladurai, P., \& Saleh, S. D. (2016). Dimensions of Leader Behavior in Sports: Development of a Lead- 
ership Scale. Journal of Sport Psychology. https://doi. org/10.1123/jsp.2.1.34

Dunn, J. G. H., Dunn, J. C., \& Syrotuik, D. G. (2002). Relationship Between Multidimensional Perfectionism and Goal Orientations in Sport. Journal of Sport \& Exercise Psychology Anshel, 24, 376-395. Retrieved from http://fitnessforlife.org/AcuCustom/Sitename/Documents/DocumentItem/173.pdf

Fedewa, B. A., Burns, L. R., \& Gomez, A. A. (2005). Positive and negative perfectionism and the shame/ guilt distinction: Adaptive and maladaptive characteristics. Personality and Individual Differences. https://doi. org/10.1016/j.paid.2004.09.026

Flett, G. L., Hewitt, P. L., \& Hill, A. P. (2016). Reflections on perfection and the pressure to be perfect in athletes, dancers, and exercisers: A focus on perfectionistic reactivity in key situations and life contexts. In The psychology of perfectionism in sport, dance and exercise.

Gesualdo, S. (2011). Scholarship at UWindsor Investigating the Role of Gender on Athlete Leadership and Coaching Behaviours. Retrieved from http://scholar.uwindsor. ca/etd

Hamidi, S., \& Besharat, M. A. (2010). Perfectionism and competitive anxiety in athletes. In Procedia - Social and Behavioral Sciences (Vol. 5, pp. 813-817).

Hewitt, P. L., Flett, G. L., \& Ediger, E. (1995). Perfectionism traits and perfectionistic self-presentation in eating disorder attitudes, characteristics, and symptoms. International Journal of Eating Disorders. https:// doi.org/10.1002/1098-108X(199512)18:4<317:AIDEAT2260180404>3.0.CO;2-2

Jurko, D., Tomljanović, M., \& Čular, D. (2013). Initial Validation of Coaching Behavior Scales in Volleyball. Sport Scientific and Practical \ldots, 10(1), 47-50.

Kenow, L., \& Williams, J. (2016). Relationship between Anxiety, Self-Confidence, and Evaluation of Coaching Behaviors. The Sport Psychologist. https://doi. org/10.1123/tsp.6.4.344
Lameiras, J., Martins, B., Lopes-De-Almeida, P., \& García-Mas, A. (2017). Athletes Perception of Coaches' Leadership Style and Tendency to Cooperate among Competitive Teams. Acción Psicológica. https://doi. org/10.5944/ap.14.1.19264

Nordin-Bates, S. M., Hill, A. P., Cumming, J., Aujla, I. J., \& Redding, E. (2014). A longitudinal examination of the relationship between perfectionism and motivational climate in dance. Journal of Sport \& Exercise Psychology, 36(4), 382-391. https://doi.org/10.1123/jsep.2013-0245

Sagar, S. S., \& Stoeber, J. (2009). Perfectionism, Fear of Failure, and Affective Responses to Success and Failure: The Central Role of Fear of Experiencing Shame and Embarrassment. Journal of Sport and Exercise Psychology, 31, 602-627. https://doi.org/10.1037//1082-989x.7.4.422 Sari, I., Bayazlt, B., Soyer, F., Sarı, İ., \& Talaghir, L.-G. (2017). The Relationship between Perceived Coaching Behaviours, Motivation and Self-Efficacy in Wrestlers. Procedia - Social and Behavioral Sciences. https://doi. org/10.1515/hukin-2017-0065

Sassaroli, S., Romero Lauro, L. J., Maria Ruggiero, G., Mauri, M. C., Vinai, P., \& Frost, R. (2008). Perfectionism in depression, obsessive-compulsive disorder and eating disorders. Behaviour Research and Therapy. https://doi. org/10.1016/j.brat.2008.02.007

Đurović, D., Sokić, J., i Aleksić Veljković, A. (2017). Perfekcionizam i specifična ponašanja trenera u pojavi poremećaja ishrane u estetskim sportovima. 5. kongres psihologa Bosne i Hercegovine, 2-4. Mart, Društvo psihologa Republike Srpske.

\section{Corresponding author:}

Dr. Aleksandra Aleksić Veljković, Assistant Professor

Faculty of Sport and Physical Education, Čarnojevića 10a, 18000 Niš, Serbia E-mail: aleksic.veljkovic@gmail.com 